\title{
Article \\ Gold Inks for Inkjet Printing on Photo Paper: Complementary Characterisation
}

\author{
Hanuma Reddy Tiyyagura ${ }^{1,2}$, Peter Majerič ${ }^{1,2}$, Matej Bračič ${ }^{1}\left(\right.$, Ivan Anžel ${ }^{1}$ and Rebeka Rudolf ${ }^{1,2, * \mathbb{C}}$ \\ 1 Faculty of Mechanical Engineering, University of Maribor, Smetanova ulica 17, 2000 Maribor, Slovenia; \\ hanuma.tiyyagura@um.si (H.R.T.); peter.majeric@um.si (P.M.); matej.bracic@um.si (M.B.); \\ ivan.anzel@um.si (I.A.) \\ 2 Zlatarna Celje d.o.o., Kersnikova ulica 19, 3000 Celje, Slovenia \\ * Correspondence: rebeka.rudolf@um.si
}

check for updates

Citation: Tiyyagura, H.R.; Majerič, P.; Bračič, M.; Anžel, I.; Rudolf, R. Gold Inks for Inkjet Printing on Photo Paper: Complementary Characterisation. Nanomaterials 2021, 11, 599. https://doi.org/10.3390/ nano11030599

Academic Editor: Horacio Bach

Received: 1 February 2021

Accepted: 24 February 2021

Published: 28 February 2021

Publisher's Note: MDPI stays neutral with regard to jurisdictional claims in published maps and institutional affiliations.

Copyright: (c) 2021 by the authors. Licensee MDPI, Basel, Switzerland. This article is an open access article distributed under the terms and conditions of the Creative Commons Attribution (CC BY) license (https:// creativecommons.org/licenses/by/ $4.0 /)$.

\begin{abstract}
Nowadays, cost-effective, available, and flexible paper-based electronics play an essential role in the electronics industry. Herein, we present gold nanoparticles (AuNPs) as a potential raw material for gold inks in the future for such purposes. AuNPs in this research were synthesised using the ultrasonic spray pyrolysis (USP) technique from two precursors: gold (III) chloride tetrahydrate and gold (III) acetate. Synthesised AuNPs were collected in a suspension composed of deionised (D.I.) water and the stabiliser polyvinylpyrrolidone (PVP). AuNPs' suspensions were subjected to the rotavapor process to obtain gold inks with higher Au concentration (>300 ppm). ICP-MS mea-

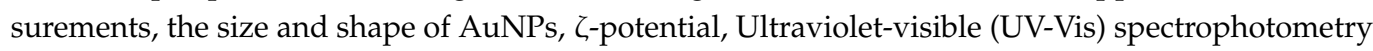
measurements, and scanning electron microscop y (SEM) of gold inks were carried out in order to find the optimal printing parameters. In the final stage, the optical contact angle measurements were performed using a set of polar to non-polar liquids, allowing for the determination of the surface free energy of gold inks. Inkjet printing of gold inks as defined stripes on photo paper were tested, based on the characterisation results.
\end{abstract}

Keywords: gold nanoparticles; ultrasonic spray pyrolysis; gold inks; characterisation; inkjet printing

\section{Introduction}

In recent years, printed paper electronics have gained attention in various applications, like electrochemical sensors, energy storage devices, solar cells, and radiofrequency identification tags [1-9]. Paper-based inkjet-printed flexible electronic circuits with costeffective recyclability, and ecological features, are an alternative to the ongoing current electronic devices [10-12]. Different types of printing techniques are available in the market to fabricate paper electrodes, such as photolithography [13,14], screen printing [15,16], the drop-on-demand inkjet printing technique [17-20], etc. Among these, inkjet printing is one of the easy and non-contact direct ink writing methods for printing paper electrodes with high resolution and precision without a mask pattern compared to other printing techniques. For inkjet printing, conductive inks are used, composed mostly on the basis of metallic nanoparticles like silver, copper, and gold [21,22]. Especially, gold nanoparticles (AuNPs) are applied widely in electronics, sensors, probes, catalysis, and photochemical therapy, due to their unique properties [23-26]. AuNPs are, namely, highly conductive and biocompatible, besides possessing surface plasmon resonance and special optical and electronic properties, depending on their sizes and shapes [27,28].

Based on the presented "state-of-the-art" for printed paper electronics, our main research focus was to prepare a low cost, stable, and useful gold ink, which can easily be used for inkjet printing on different types of paper; photo paper was used for testing in this study. ultrasonic spray pyrolysis (USP) bottom-up and the rotavapor process were applied for preparation of two types of gold inks, which differed in the chemical composition of the precursor. The flexibility of the USP method allows it to produce AuNPs and, subsequently, 
gold ink, from various precursor salts and in differing shapes and sizes. Feasibility studies were performed for preparing and using gold ink from the USP method $[27,28]$. However, there were some gaps in the literature and research regarding the properties of the prepared inks and their usability in inkjet printing. The physical properties of the prepared gold inks were explained with the different characterisation techniques; in addition, their surface behaviour was explained with the help of optical contact angle and surface energy measurements in order to perform optimal printing. Finally, the quality of the printed strips was determined and characterised. This study highlights the properties of the different gold inks produced by USP, for determining the most applicable ink for printing.

\section{Materials and Methods}

\subsection{Materials}

Starting materials for the preparation of Au precursors: gold (III) chloride tetrahydrate$\mathrm{AuCl}$ (trace metals basis 99.9\%, Acros Organics, Nidderau, Germany) and Au acetate saltAuAc (gold (III) acetate, Alfa Aesar, Haverhill, MA, USA). Collection medium: deionised water (D.I.) and polyvinylpyrrolidone (PVP40 Sigma Aldrich, Darmstadt, Germany). Other chemicals: sodium hydroxide ( $\mathrm{NaOH}$, Fisher Chemicals, Geel, Germany) and hydrochloric acid ( $\mathrm{HCl}, 37 \%$, Sigma Aldrich, Taufkirchen, Germany).

\subsection{Methods}

\subsubsection{Preparation of AuNPs}

AuNPs were produced with a USP device located in Zlatarna Celje d.o.o., Celje, Slovenia. The USP device uses a custom-made ultrasonic generator with a $1.6 \mathrm{MHz}$ ultrasonic transducer LIQUIFOG II (Johnson Matthey Piezo Products GmbH, Redwitz, Germany) as its base [29-31]. The ultrasonic generator produces aerosol droplets from the Au precursor, which are transported by carrier gas $\left(\mathrm{N}_{2}\right)$ into a heating furnace, which is composed of 3 zones. The first zone is evaporative, and the second zone is reactive, where $\mathrm{H}_{2}$ enters, resulting in thermal decomposition of the dried $\mathrm{Au}$-ions and in reduction in the $\mathrm{Au}^{3+}$ into $\mathrm{Au}^{0}$ as AuNPs. The sintering of AuNPs is carried out in the third zone. AuNPs are finally collected in four serially connected gas washing bottles in D.I water and PVP $(1 \mathrm{~g} / \mathrm{L})$ - as presented in Figure 1.

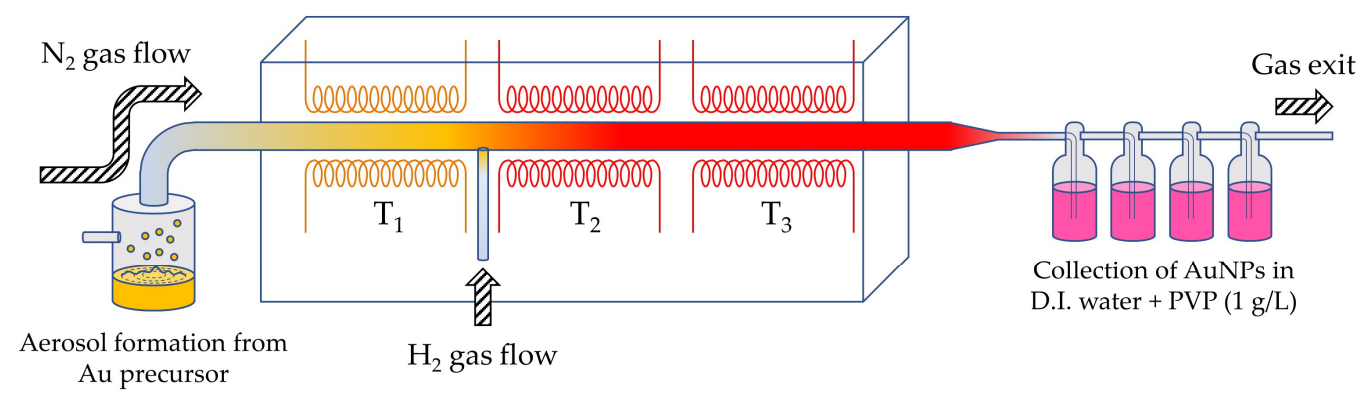

Figure 1. A schematic presentation of the ultrasonic spray pyrolysis (USP) device used for the synthesis of gold nanoparticles (AuNPs).

For preparation of both precursors, two key Au concentrations $(0.5$ and $1 \mathrm{~g} / \mathrm{L})$ were chosen, that represented four different types of precursors: AuAc $0.5 \mathrm{~g} / \mathrm{L}, \mathrm{AuAc} 1 \mathrm{~g} / \mathrm{L}$, $\mathrm{AuCl} 0.5 \mathrm{~g} / \mathrm{L}$, and $\mathrm{AuCl} 1 \mathrm{~g} / \mathrm{L}$ (these names are used throughout the text). The temperature $\left(\mathrm{T}_{1}, \mathrm{~T}_{2}\right.$, and $\left.\mathrm{T}_{3}\right)$ and gas $\left(\mathrm{N}_{2}\right.$ and $\left.\mathrm{H}_{2}\right)$ flows in the heating furnace were consistent with previous experiments $[27,28]$. The detailed parameters of the USP synthesis are the subject of an applied patent for AuNP production [32]. The volume of each collected AuNPs' suspension was $1 \mathrm{~L}$. 


\subsubsection{Preparation of Gold Inks}

Each AuNPs' suspension was concentrated using Rotavopor distillation (Rotavopor (BUCHI Rotavapor R-300, BÜCHI Labortechnik AG, Flawil, Switzerland) with the same parameters. The distillation parameters were: (1) pressure- $40 \mathrm{mBar}$, (2) speed of rotation of the evaporating flask $-240 \mathrm{rpm}$, (3) heating bath temperature $-40{ }^{\circ} \mathrm{C}$, (4) the initial volume of suspension-250 $\mathrm{mL} \times 4$, (5) $1000 \mathrm{~mL}$ of each suspension was concentrated to $50 \mathrm{~mL}$ and the final volume of suspension-12.5 $\mathrm{mL} \times 4$, and (6) distillation time$1 \mathrm{~h} \times 4=4 \mathrm{~h}$. Figure 2 shows the prepared gold inks AuAc $1 \mathrm{~g} / \mathrm{L}$ and $\mathrm{AuCl} 1 \mathrm{~g} / \mathrm{L}$. Colloidal stability of the inks was evaluated by turbidity measurements (TB1 Turbidimeter, Velp Scientifica, Usmate Velate (MB), Italy) over a period of 4 weeks in which the inks remained stable, hence appropriate for ink-jet printing. The $\mathrm{AuCl} 1 \mathrm{~g} / \mathrm{L}, \mathrm{AuAc} 1 \mathrm{~g} / \mathrm{L}, \mathrm{AuCl}$ $0.5 \mathrm{~g} / \mathrm{L}$, and AuAc $0.5 \mathrm{~g} / \mathrm{L}$ inks exhibited "ejectability" numbers of 5.75, 5.80, 5.82, and $5.651 / \mathrm{Oh}$, respectively.
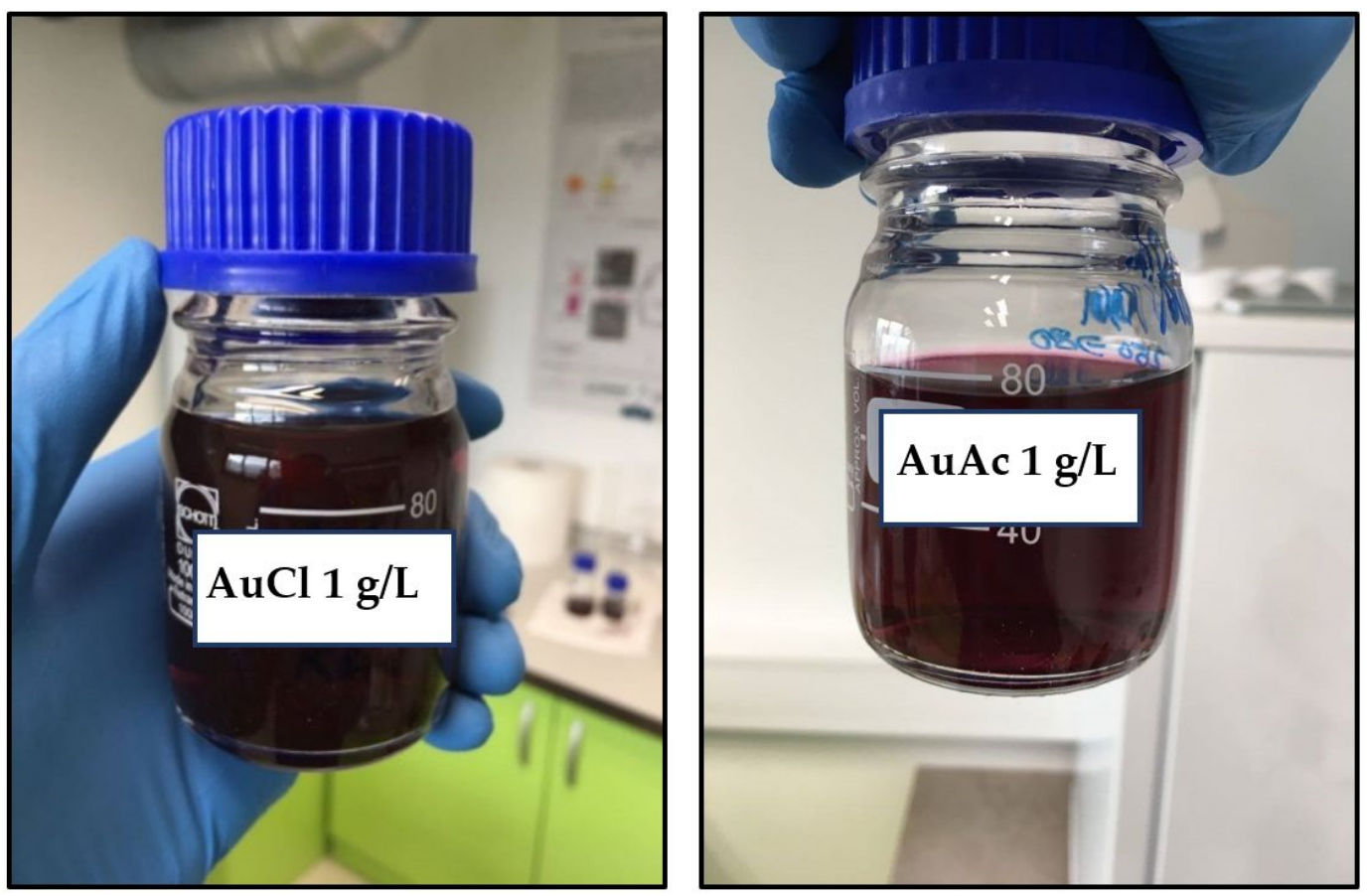

Figure 2. Prepared gold inks gold (III) chloride tetrahydrate ( $\mathrm{AuCl})$ and $\mathrm{Au}$ acetate salt $(\mathrm{AuAc})$ with Au concentration of $1 \mathrm{~g} / \mathrm{L}$ in the precursor.

\subsubsection{Inkjet Printing}

A Dimatix Fujifilm inkjet Printer DMP-2831 (Fujifilm, Santa Clara, CA, USA) with a piezoelectric ink cartridge (with a drop volume of $10 \mathrm{pL}$ ) equipped with a fiducial camera, was used for the testing of inject printing of gold inks onto the photo paper. Characteristic parameters were: jetting voltage for all nozzles: $23 \mathrm{~V}$, tickle control (frequency): $23 \mathrm{kHz}$, head angle: $4.5^{\circ}$, cartridge temperature: $28^{\circ} \mathrm{C}$; platen temperature: $60^{\circ} \mathrm{C}$. The choice of photo paper was random as it was available in the laboratory. The printed pattern dimensions were $60 \mathrm{~mm} \times 9 \mathrm{~mm}$ (Figure 3 ).

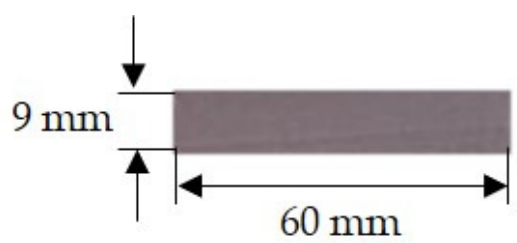

Figure 3. Presentation of gold ink-printed pattern on photopaper. 


\subsection{Characterisation}

\subsubsection{Inductively Coupled Plasma-Mass Spectrometry (ICP-MS)}

The concentration of synthesised AuNPs in all four prepared gold inks was measured with inductively coupled plasma-mass spectrometry (ICP-MS). The spectrometer used was an HP, Agilent 7500 CE, equipped with a collision cell (Santa Clara, CA, USA). The following conditions were used for the ICP-MS: the power was $1.5 \mathrm{~kW}$, Nebuliser-Meinhard, plasma gas flow was $15 \mathrm{~L} / \mathrm{min}$, nebuliser gas flow was $0.85 \mathrm{~L} / \mathrm{min}$, make up gas flow was $0.28 \mathrm{~L} / \mathrm{min}$, and reaction gas flow was $4.0 \mathrm{~mL} / \mathrm{min}$. The instrument was calibrated with matrix-matched calibration solutions. The relative measurement uncertainty was estimated as $\pm 3 \%$.

\subsubsection{Dynamic and Electrophoretic Light Scattering (DLS)}

A Zetasizer Nano ZS device (Malvern Instruments Ltd., Malvern, UK) was used to determine the mean hydrodynamic diameter $(\mathrm{d} \mathrm{nm})$ and the $\zeta$-potential of the AuNPs in gold inks by dynamic (DLS) and electrophoretic light scattering (ELS) of the particles. The DLS measurements were conducted using a $633 \mathrm{~nm}$ light source and a scattering angle of $173^{\circ}$. Slow and fast field reversal measurements were performed in the electrophoretic mobility experiments. All measurements were performed at $25^{\circ} \mathrm{C}$ using water $(\mathrm{RI}=1.33$, viscosity $=0.8872 \mathrm{CP}$, and dielectric constant $=78.5$ ) as the dispersant for calculation of the results. Measurements were performed in triplicates.

\subsubsection{UV-VIS Spectrophotometry}

A Tecan Infinite M200 UV/VIS Spectrophotometer (Tecan, Salzburg, Austria), using a quartz cuvette, was used for the UV/VIS absorption, measured over the wavelength range of $400-750 \mathrm{~nm}$, with number of flashes $=5 \times$ and time per measure $=20 \mathrm{~ms}$.

\subsubsection{Scanning Electron Microscopy}

A scanning electron microscope, Sirion 400NC (FEI, FEI, Hillsboro, OR, USA), with an energy-dispersive X-ray spectroscope, INCA 350 (Oxford Instruments, Oxford, UK), was used for the SEM/EDS analysis. It had a Schottky electron source, where the field emission produces a jet of electrons with a small diameter and a high density. The result is high resolution, even at low voltages: $1.0 \mathrm{~nm}$ at $15 \mathrm{kV}$ and $2.0 \mathrm{~nm}$ at $1 \mathrm{kV}$. The AuNPs' suspensions were put dropwise onto the SEM holders (mesh) with conductive carbon adhesive tape, which allowed better SEM observation. The SEM holders were left to dry in a desiccator for 1 day before the SEM investigations were carried out.

\subsubsection{Optical Goniometry}

An optical goniometer, OCA 35 (DataPhysics, Filderstadt, Germany), was used to measure the time-dependent static contact angle of the water (SWCA) and static contact angles (SCA) of all four gold inks with varying surface tensions (water, ethylene glycol, formamide, and diiodomethane) on the surfaces of gold inks' printed photo paper. The time-dependent measurements $(\mathrm{t})$ were conducted automatically at a time rate of $1 \mathrm{~s}^{-1}$, and the contact angle $(\theta)$ was evaluated by ellipse fitting. A drop volume of $3 \mu \mathrm{L}$ was used to measure the contact angles at three different spots on the photo paper. Measurements were conducted under ambient conditions $\left(\mathrm{T}=25^{\circ} \mathrm{C}\right.$, relative humidity $\left.=55 \%\right)$. The surface free energy $\left(\gamma_{s}^{T O T}\right)$ of the photo papers was calculated using the SCA values of the four chosen liquids by the acid-base approach of Good, van Oss, and Chaudhury (GvOC), which divides the $\gamma_{s}^{T O T}$ into the dispersive Lifshitz-van der Waals interactions $\left(\gamma_{s}^{L W}\right)$ and the polar Lewis acid-base interactions $\left(\gamma_{s}^{A B}\right)$, as shown in Equation (1). A detailed description of the theory can be found elsewhere [33].

$$
\gamma_{s}^{T O T}=\gamma_{s}^{L W}+\gamma_{s}^{A B}=\gamma_{s}^{L W}+2\left(\sqrt{\gamma_{s}^{+} \gamma_{s}^{-}}\right)
$$


where $\gamma_{s}^{+}$and $\gamma_{s}^{-}$are the electron acceptor (Lewis acid) and electron donor (Lewis base) components, respectively. Combined with the Young's equation, the relationship for the work of adhesion between a liquid and a solid can be derived as:

$$
W_{a d h}=\gamma_{L}(1+\cos \theta)=2\left(\sqrt{\gamma_{L}^{L W} \gamma_{s}^{L W}}\right)+2\left(\sqrt{\gamma_{L}^{+} \gamma_{s}^{-}}\right)+2\left(\sqrt{\gamma_{L}^{-} \gamma_{s}^{+}}\right)
$$

where the subscripts $L$ and $s$ refer to liquid and solid, respectively. The time-dependent SCA ( $t$ ) of individual inks on the neat photo paper were measured additionally, to observe their wetting of the photo paper in comparison to pure water.

\subsubsection{Statistics}

Image software (version 1.51, NIH, Bethesda, MD, USA) was used for the size measurements of AuNPs from the SEM micrographs. A total of 1000 AuNPs were measured for each of the gold inks. Bin sizes of 10 and $5 \mathrm{~nm}$ were used for the size distribution representations. Mean values were calculated from the measured particle sizes for each sample for the SEM investigation. The mean values and standard deviations for the DLS size measurements with distributions and $\zeta$-potential measurements of AuNPs were given by the Malvern Zetasizer measurement software 7.12, (Malvern Instruments Ltd., Malvern, UK)

\section{Results and Discussion}

\subsection{ICP-MS}

The measured final concentrations of $\mathrm{Au}$ in all the prepared gold inks are shown in Table 1. We found out that higher concentrations of $\mathrm{Au}$ in the precursor allowed the formation of gold ink with a higher final AuNPs' content under the same conditions. It was discovered that, under the same gold ink preparation conditions, the final Au concentration was higher in both AuAc precursors in comparison with $\mathrm{AuCl}$. This can be attributed to the lower losses of AuNPs in the USP synthesis process from AuAc precursors and the formation of more favourable and stable AuNPs' structures in suspensions. On the other hand, there was no detectable effect of ionic strength on the final concentration of AuNPs in gold inks, which is consistent with previous research [34].

Table 1. Au concentration in the prepared gold inks.

\begin{tabular}{cc}
\hline Gold Ink & Au Concentration (ppm) \\
\hline $\mathrm{AuCl} 0.5 \mathrm{~g} / \mathrm{L}$ & 300 \\
$\mathrm{AuCl} 1.0 \mathrm{~g} / \mathrm{L}$ & 400 \\
$\mathrm{AuAc} 0.5 \mathrm{~g} / \mathrm{L}$ & 340 \\
$\mathrm{AuAc} 1.0 \mathrm{~g} / \mathrm{L}$ & 450 \\
\hline
\end{tabular}

\subsection{AuNPs' Size and $\zeta$-Potential of Gold Inks}

As can be seen in Figure 4, the AuNPs in the prepared gold inks exhibit Z-average hydrodynamic diameters ranging from $99.09 \pm 3.24 \mathrm{~nm}(\mathrm{AuCl} 1 \mathrm{~g} / \mathrm{L})$ to $115.92 \pm 1.87 \mathrm{~nm}$ $(\mathrm{AuCl} 0.5 \mathrm{~g} / \mathrm{L})$. The rather insignificant differences in Z-average values between different samples show that neither the type of precursors, nor the AuNPs' concentration influences their average hydrodynamic diameter in the gold inks. The Z-average range for all measured inks was suitable for inkjet printing, as the diameter of the printing nozzles was 21 $\mu \mathrm{m}$ [35]. However, the polydispersity index (PDI) of the AuNPs in the gold inks was rather high, as it ranged from $0.279(\mathrm{AuCl} 0.5 \mathrm{~g} / \mathrm{L}$ ) to 0.403 (AuAc $0.5 \mathrm{~g} / \mathrm{L}$ ). The PDI values seemed consistent with data reported by other authors [36]. Nevertheless, the size, shape, and PDI can vary greatly, depending on the PVP concentration during nanoparticle preparation [37]. Particles of over $1 \mu \mathrm{m}$ in size were detected as well, which poses a problem for ink jet printing, as agglomerates of $\mu \mathrm{m}$ sizes can cause nozzle blockage [35]. Therefore, prior to ink jet printing, all inks were filtered through a PTFE syringe filter with a pore diameter of 
$0.1 \mu \mathrm{m}$. Interestingly, when looking at the $\zeta$-potential data, one can observe low average values ranging from $-1.51 \pm 25.34 \mathrm{mV}(\mathrm{AuCl} 1 \mathrm{~g} / \mathrm{L})$ to $-2.89 \pm 20.68 \mathrm{mV}(\mathrm{AuCl} 0.5 \mathrm{~g} / \mathrm{L})$. The influence of increasing PVP concentration and molecular weight is known to reduce the absolute $\zeta$-potential values of negatively charged inorganic particles [38]. This agrees with the concentration and molecular weight of the PVP used in this work. Similarly, low $\zeta$-potential values were obtained by other authors as well [36]. The high standard deviation of the $\zeta$-potential values reflects a broad $\zeta$-potential distribution, resulting from the broad distribution of electrophoretic mobility, hence, charges in the inks. This can be a contribution of the negatively charged free PVP, PVP neutralised AuNPs, and the cationic nature of uncoated dissociated AuNPs [36].
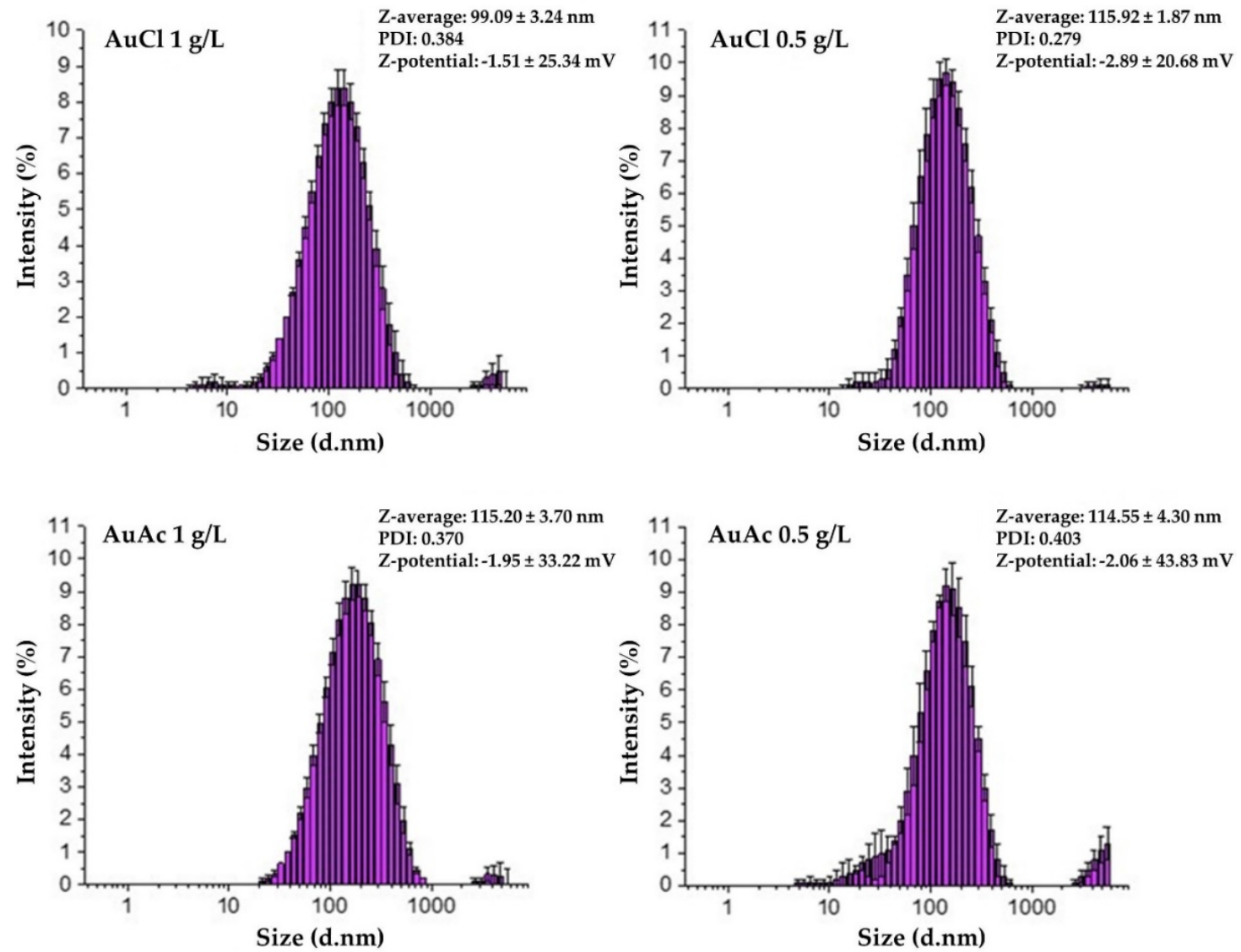

Figure 4. AuNPs' size (hydrodynamic diameter) distribution by intensity, polydispersity index (PDI), and $\zeta$-potential values for the as prepared gold inks.

\subsection{UV-VIS}

The various states of the PVP and AuNPs in gold inks were not studied further in this work. Figure 5 shows the UV-VIS spectra of the prepared gold inks within the range of 510-560 nm [39], which exhibits their unique optical properties, along with a property known as surface plasmon resonance. 


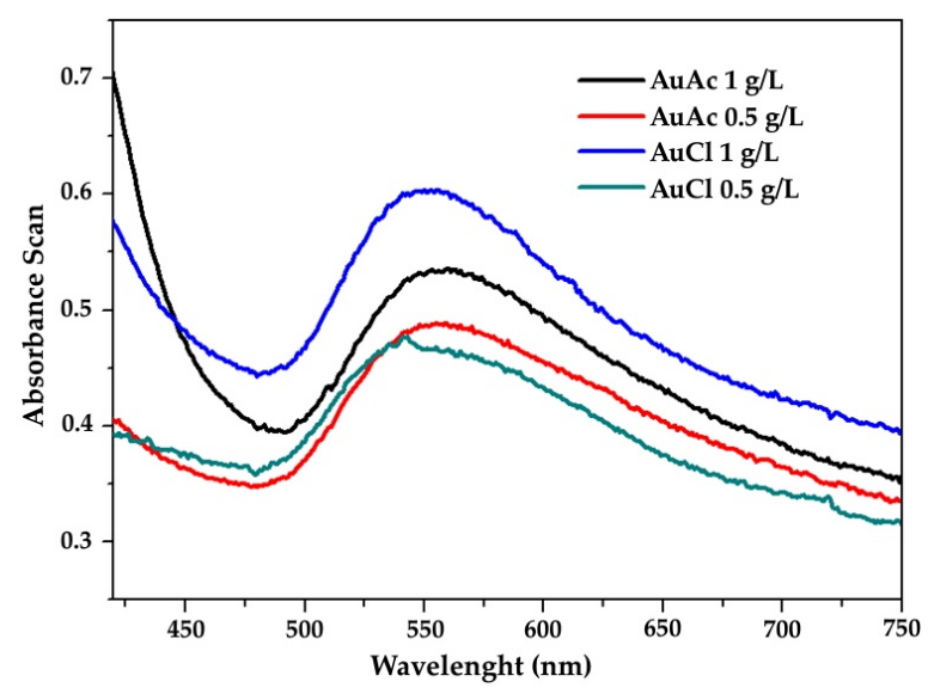

Figure 5. UV-Vis spectra of different concentrations of AuNPs.

\subsection{SEM Analysis of AuNPs}

Figure 6 shows the SEM micrographs of the AuNPs taken from suspensions synthesised through USP. The image inserts show the AuNPs' morphologies, and their size distribution is given for comparison of all suspensions. The size distributions were composed of 1000 ImageJ AuNPs' size measurements for each sample, obtaining a general overview of the particle sizes. The acquired size distributions are in agreement with the sizes given from DLS measurements, with small deviations between the results of the two measurement methods. From the SEM micrographs, there is also a well visible difference in the AuNPs' morphology. AuNPs in $\mathrm{AuCl}$ suspensions have mostly spherical and irregularly shaped particles; AuAc $1 \mathrm{~g} / \mathrm{L}$ has similar AuNPs shapes, mostly spherical with some irregular particles. AuAc $0.5 \mathrm{~g} / \mathrm{L}$ has more irregular AuNPs present, along with spherical particles, while the irregular particles are also somewhat bigger than the spherical ones. The measured size distribution for this sample was even more erratic, not showing a clear peak for the sizes of the AuNPs that were measured. The irregular AuNPs were also more difficult to measure in a relevant way, as they had different dimensions in a single shape. The largest dimensions of these AuNPs were chosen for the measurements.

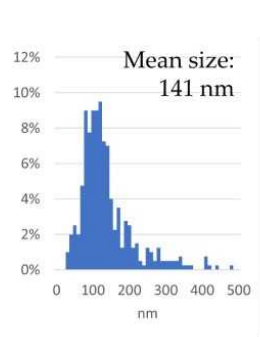

$\mathrm{AuCl} 1 \mathrm{~g} / \mathrm{L}$
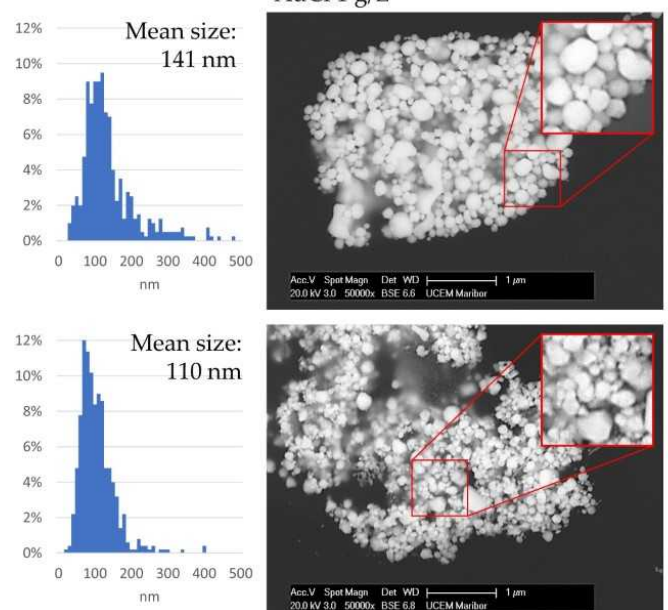

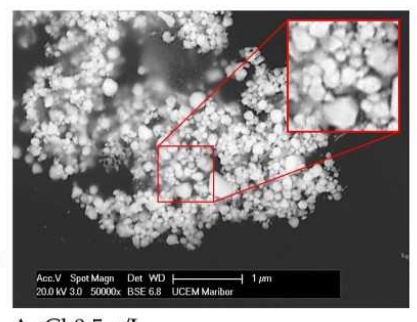

$\mathrm{AuCl} 0.5 \mathrm{~g} / \mathrm{L}$
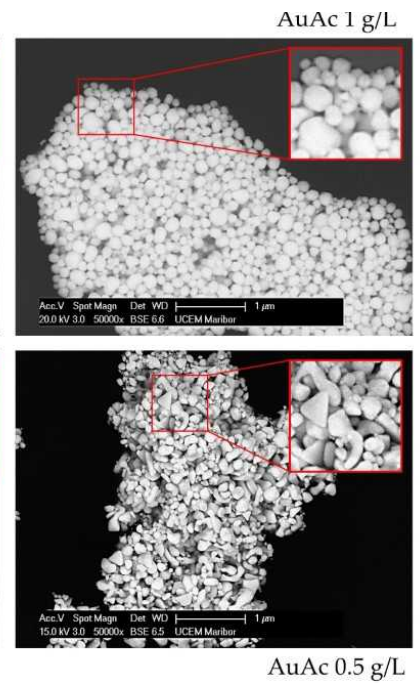

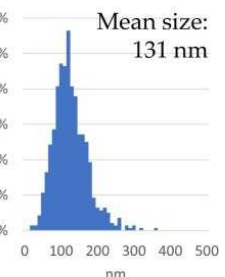

$\mathrm{nm}$

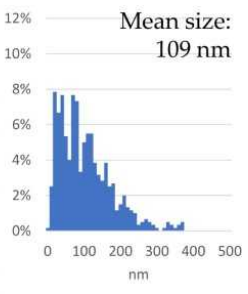

Figure 6. SEM micrographs of AuNPs taken from suspensions synthesised through USP, with corresponding size distributions from ImageJ. 
After filtration of the AuNPs in suspensions through a PTFE syringe filter, the SEM investigation was repeated for the samples, as shown in Figure 7. A much higher number of smaller AuNPs was detected in the AuCl samples' measurements than with the AuAc samples. The filter pore diameter of $0.1 \mu \mathrm{m}$ dictated that the filtered AuNPs should have a size below $100 \mathrm{~nm}$; however, it seems to have also been more effective for the $\mathrm{AuCl}$ samples, acting as a barrier for all but the smallest AuNPs' sizes. This resulted in smaller mean sizes of about $20 \mathrm{~nm}$, and a sharper, more narrow size distribution as compared to the AuAc samples. This outcome of filtration may be due to the different chemical constituents remaining in the suspensions produced with USP and the surface charges of the resulting particles. An important note is that only 1000 AuNPs were measured from the samples, and this investigation showed an overview of the sample conditions. However, it was evident from this investigation that although the larger AuNPs may also have been present in the $\mathrm{AuCl}$ samples, they were present in far fewer numbers compared to particles of $50 \mathrm{~nm}$ and lower.
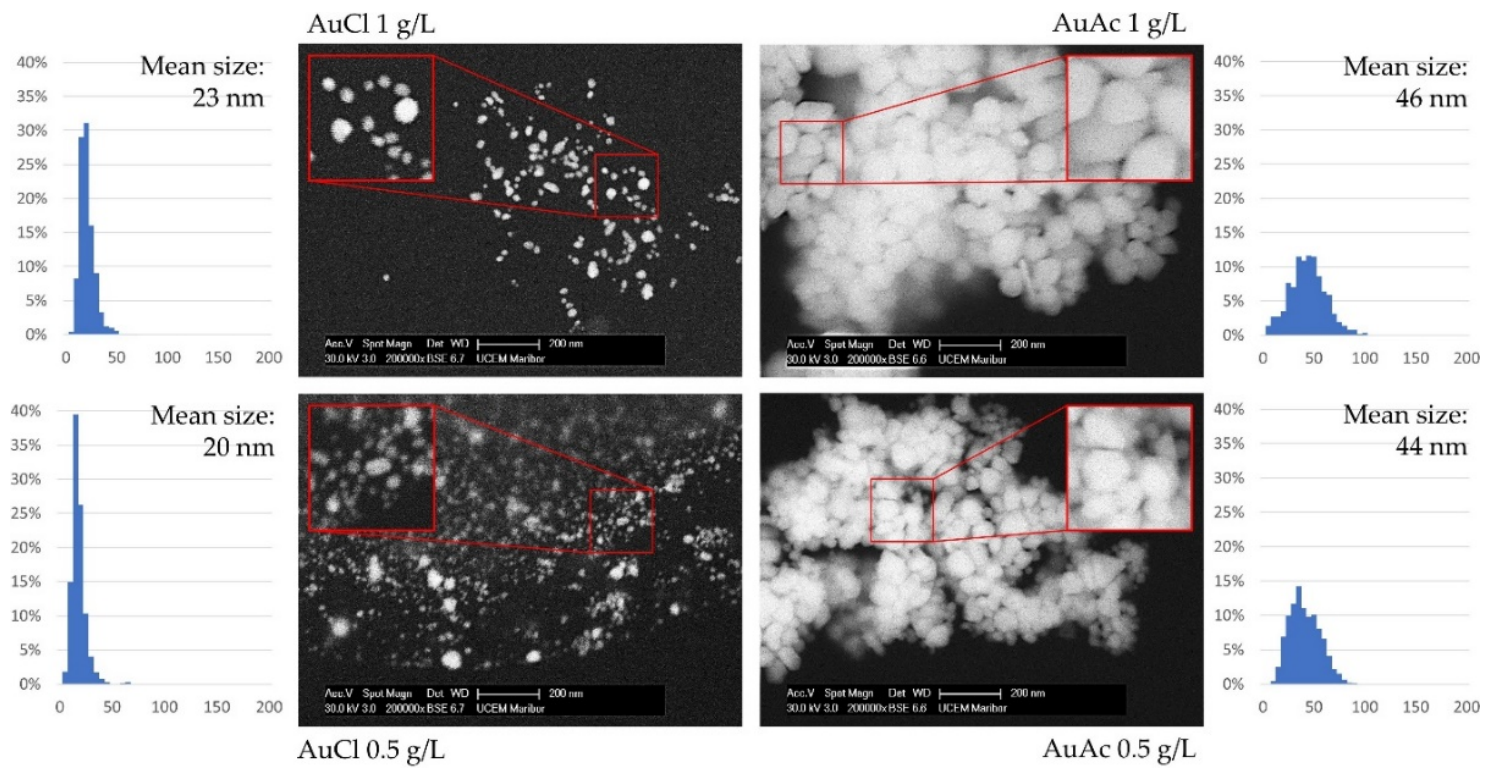

Figure 7. SEM micrographs of AuNPs taken from filtered suspensions, with corresponding size distributions from ImageJ.

\subsection{Contact Angle and Surface Energy Measurements of Gold Inks}

As can be observed in Figure 8A, the SWCA(t) of the inkjet-printed AuNPs on photo paper showed a faster rate of change of SWCA over time than the neat photo paper. The SWCA $(\mathrm{t})$ of neat photo paper changed from the initial $56.0^{\circ}$ (at $0 \mathrm{~s}$ ) to $51.0^{\circ}$ (at $70 \mathrm{~s}$ ) at an average rate of $0.07 \pm 0.09^{\circ} / \mathrm{s}$. This can be attributed largely to water evaporation from the drop, and less to absorption and wetting of the paper. This was confirmed by running the same experiment on a non-absorptive surface, i.e., a silicon wafer (Figure 8A). The contact angle, in this case, changed from the initial $65.0^{\circ}$ (at $0 \mathrm{~s}$ ) to $59.8^{\circ}$ (at $70 \mathrm{~s}$ ) at an average rate of $0.07 \pm 0.05$. This is a reflection of evaporation, as water cannot get absorbed by the non-absorptive wafer. The same can be concluded for water on photo paper, as the rate of SWCA (t) change was the same as in the case of the silicon wafer. On the contrary, the SWCA(t) of $\mathrm{AuCl} 1 \mathrm{~g} / \mathrm{L}$ changed at a rate of $2.23 \pm 1.73^{\circ} / \mathrm{s}$ in the first $10 \mathrm{~s}$ from $37.4^{\circ}$ to $18.5^{\circ}$, indicating wetting of the printed paper by water molecules over time. It is worth noticing that, in the first $3 \mathrm{~s}$, the rate changed at the highest rate of $5.13^{\circ} / \mathrm{s}$, which reflects the fast-spreading of water on the AuNPs' print. After that, the SWCA(t) changed at an average rate of $0.13 \pm 0.13^{\circ} / \mathrm{s}$, indicating that water evaporation was driving the SWCA $(\mathrm{t})$ change instead of paper wetting. A similar trend was observed in the case of AuAc $1 \mathrm{~g} / \mathrm{L}$, where the SWCA $(\mathrm{t})$ changed at an average rate of $1.23 \pm 0.50 \% \mathrm{~s}$ in the first $10 \mathrm{~s}$ from $35.3^{\circ}$ to $24.2^{\circ}$. The highest rate in the first $3 \mathrm{~s}$ was $1.99^{\circ} / \mathrm{s}$, which was more than 2-fold 
lower than in the case of $\mathrm{AuCl}$ gold inks. Although the rate was lower when compared to $\mathrm{AuCl} 1 \mathrm{~g} / \mathrm{L}$, wetting of the gold inks-printed paper can be confirmed. The rate dropped to an average of $0.26 \pm 0.22^{\circ} / \mathrm{s}$ between 10 and $70 \mathrm{~s}$. Similar behaviour can be observed at lower ink concentrations, although the initial SWCA(t) rates were lower, which points to a slower wetting of the printed paper than in the case of $1 \mathrm{~g} / \mathrm{L}$ ink. This can be related to thinner prints in the case of $0.5 \mathrm{~g} / \mathrm{L}(\mathrm{h}=\mathrm{mm})$ than in $1 \mathrm{~g} / \mathrm{L}(\mathrm{h}=\mathrm{mm})$. In the case of the $\mathrm{AuCl} 0.5 \mathrm{~g} / \mathrm{L}$ ink, the SWCA(t) changed at an average rate of $0.71 \pm 0.42^{\circ} / \mathrm{s}$ in the first $10 \mathrm{~s}$ from the initial $23.8^{\circ}$ to $11.4^{\circ}$, followed by an average rate of $0.10 \pm 0.09^{\circ} / \mathrm{s}$. In the case of the AuAc $0.5 \mathrm{~g} / \mathrm{L}$ ink, the SWCA(t) changed at an average rate of $0.56 \pm 0.20^{\circ} / \mathrm{s}$ in the first $10 \mathrm{~s}$ from initial $26.9^{\circ}$ to $15.3^{\circ}$, followed by a rate of $0.11 \pm 0.08^{\circ} / \mathrm{s}$ between 10 and $70 \mathrm{~s}$. Drop images of the optical SWCA(t) measurements at 0 and $70 \mathrm{~s}$ for the neat and gold-printed photo paper are shown in Figure 8B. The results suggest that water wetting of the gold inks-printed patterns can be controlled by varying the concentration of AuNPs in the gold ink.

A)

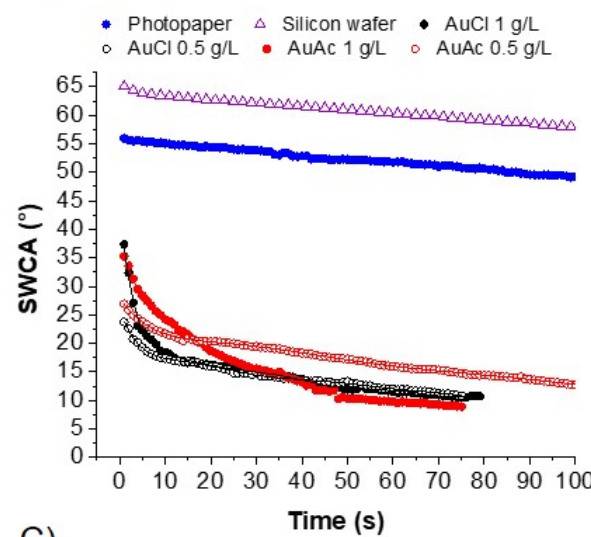

C)

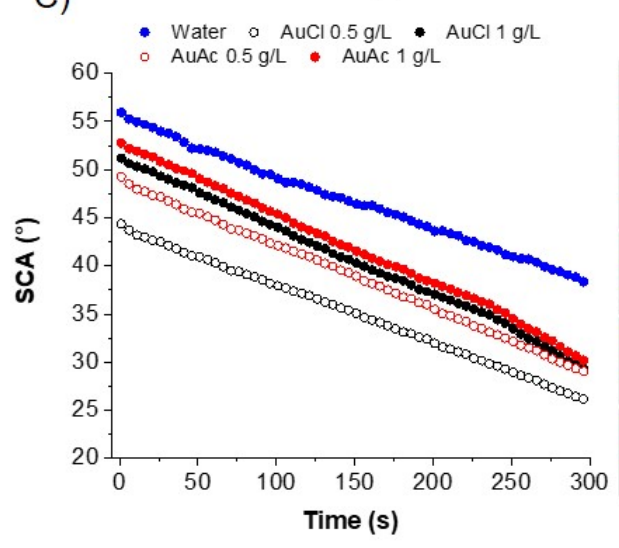

B)

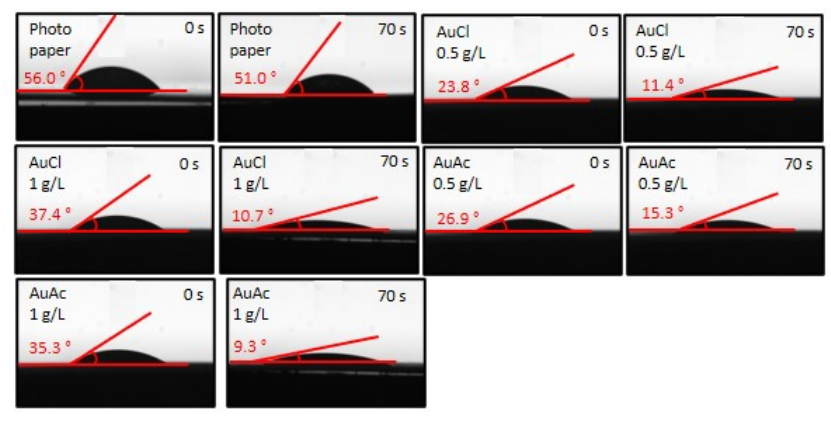

D)
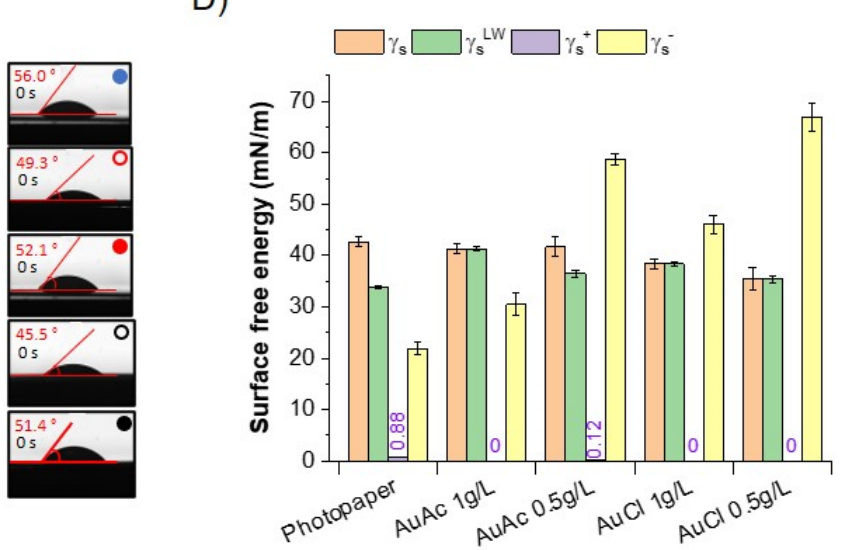

Figure 8. OCA: Optical contact angle measurements of inkjet-printed patterns from gold inks. (A) Static contact angle of the water (SWCA)(t) on neat photo paper and inkjet-printed patterns of gold inks (lines represent polynomial fits; order = 9); (B) drop images of water from SWCA(t) measurements at the time of contact $(0 \mathrm{~s})$ and after $70 \mathrm{~s}$; (C) static contact angles (SCA)(t) of water and gold inks on photo paper; and (D) surface free energy calculations of the inkjet-printed patterns from gold inks using the Good, van Oss, and Chaudhury (GvOC) approach.

The wetting of the photo paper by the gold ink itself was also studied, and the SWCA(t) and the drop images are shown in Figure $8 \mathrm{C}$. The SCA(t) of the water drop changed at an average rate of $0.07 \pm 0.09^{\circ} / \mathrm{s}$, and it changed at a similar rate of $0.06 \pm 0.05^{\circ} / \mathrm{s}$, $0.07 \pm 0.05^{\circ} / \mathrm{s}, 0.07 \pm 0.05^{\circ} / \mathrm{s}$, and $0.07 \pm 0.05^{\circ} / \mathrm{s}$ for the $\mathrm{AuCl} 0.5 \mathrm{~g} / \mathrm{L}, \mathrm{AuCl} 1 \mathrm{~g} / \mathrm{L}$, $\mathrm{AuAc} 0.5 \mathrm{~g} / \mathrm{L}$, and AuAc $1 \mathrm{~g} / \mathrm{L}$, respectively. Thus, the AuNPs in the aqueous inks did not change the water wetting behaviour of photo paper, even though the initial contact angles $(0 \mathrm{~s})$ were slightly lower than in the case of water. The lower initial contact angles 
can be attributed to the higher dispersive part of the AuNPs $\left(\gamma_{s}^{L W}=35.4-41.3 \mathrm{mN} / \mathrm{m}\right)$ in comparison with water $\left(\gamma_{s}^{L W}=21.8 \mathrm{mN} / \mathrm{m}\right)$, a contribution of the stabilising polymer PVP (Table 2 PVP). The higher dispersive part value was closer to the value of neat photo paper $(42.6 \mathrm{mN} / \mathrm{m})$, making the wettability of the inks slightly higher than water. The surface free energy of PVP was determined by Lee to be $48.5 \mathrm{mN} / \mathrm{M}$ and by Van Oss to be $43.4 \mathrm{mN} / \mathrm{M}$ (Table 2). It exhibited high dispersive $\left(\gamma_{s}^{L W}\right)$ interactions $(43.4 \mathrm{mN} / \mathrm{m})$ and rather a high electron-donating Lewis-base part $\left(\gamma_{s}^{-}=15.3-29.7 \mathrm{mNm}\right)$. When looking at the photo paper itself, the SFE of $42.6 \mathrm{mN} / \mathrm{m}$ was very similar to PVP. A slightly lower dispersive part was observed $\left(\gamma_{s}^{L W}=33.8 \mathrm{mN} / \mathrm{m}\right)$. The neat gold exhibited an SFE of $36.5 \mathrm{mN} / \mathrm{m}$, which was lower than the PVP and the photo paper. It also exhibited a dispersive part $\left(\gamma_{s}^{L W}=33.5 \mathrm{mN} / \mathrm{m}\right)$ and the Lewis-base part $\left(\gamma_{s}^{-}=19.3 \mathrm{mNm}\right)$ values similar to the photo paper.

Table 2. SFE polyvinylpyrrolidone (PVP): surface free energy of photo paper (determined experimentally), dental gold type III, and polyvinylpyrrolidone as reported in the literature.

\begin{tabular}{ccccccc}
\hline Author & Model & $\gamma_{s}(\mathrm{mN} / \mathrm{m})$ & $\gamma_{s}^{L W}$ & $\gamma_{s}^{A B}$ & $\gamma_{s}^{+}$ & $\gamma_{s}^{-}$ \\
\hline PVP by Ma et al. [13] & GvOC & 48.5 & 43.4 & 5.1 & 0.4 & 15.3 \\
PVP by Van Oss et al. [40] & GvOC & 43.4 & 43.4 & 0.0 & 0.0 & 29.7 \\
Gold by Knorr et al. [41] & Least square analysis & 36.5 & 33.5 & 3.01 & 0.17 & 19.3 \\
Photo paper (this study) & GvOC & 42.6 & 33.8 & & 0.9 & 21.9 \\
\hline
\end{tabular}

Furthermore, when looking at Figure 8D, we can see that the gold ink jet-printed patterns exhibited $\gamma_{s}$ values of $41.3 \pm 0.9,41.7 \pm 1.9,38.4 \pm 1.0$, and $35.4 \pm 2.2$ for AuAc $1 \mathrm{~g} / \mathrm{L}, \mathrm{AuAc} 0.5 \mathrm{~g} / \mathrm{L}, \mathrm{AuCl} 1 \mathrm{~g} / \mathrm{L}$, and $\mathrm{AuCl} 0.5 \mathrm{~g} / \mathrm{L}$, respectively. These values were 5-27\% lower than the theoretical values for PVP. This indicated that the interactions of the printed patterns and the liquid occurred partially on the PVP-liquid interface (higher $\gamma_{s}$ ) and partially on the gold-liquid interface (lower $\gamma_{s}$ ). This confirmed the zeta potential measurements, assuming that the inks contained a variety of charges. The increasing Lewisbase component was difficult to evaluate, as the GvOC approach overestimated it, which arose mostly from the reference values for the dispersive and polar parts used for water [32]. Therefore, the absolute values of the base parts are not discussed in greater detail.

\subsection{SEM Analysis of Printing Pattern}

The printing pattern characterisations are presented in Figure 9. SEM micrographs confirmed the presence of AuNPs on the surface of the photo paper. The formed prints showed a good distribution of AuNPs over the surface of the photo papers. Evidently, a significantly higher concentration of AuNPs was observed in those where gold inks formed from precursors with an initial higher concentration of $\mathrm{Au}=1 \mathrm{~g} / \mathrm{L}$ were used, which was also consistent with the obtained results of ICP-MS and other analyses.

$\mathrm{SEM} / \mathrm{EDX}$ analyses identified the presence of $\mathrm{Au}$, which is a direct confirmation of the AuNPs, while identification of $\mathrm{C}, \mathrm{O}, \mathrm{Al}$, and $\mathrm{Si}$ was sourced from the photo paper with a glossy coating, which was used as the testing printing substrate for the gold inks. 
A)

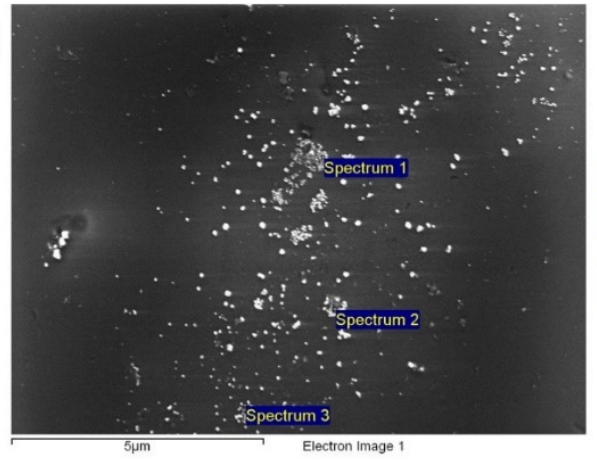

\begin{tabular}{|l|l|l|l|l|l|}
\hline Spectrum & $\mathrm{C}$ & $\mathrm{O}$ & $\mathrm{Al}$ & $\mathrm{Si}$ & $\mathrm{Au}$ \\
\hline Spectrum 1 & 40.88 & 35.16 & 10.11 & 10.08 & 3.78 \\
\hline Spectrum 2 & 42.63 & 30.56 & 8.26 & 12.16 & 6.38 \\
\hline
\end{tabular}

$33.58-9.17-9.05$
-10

B)

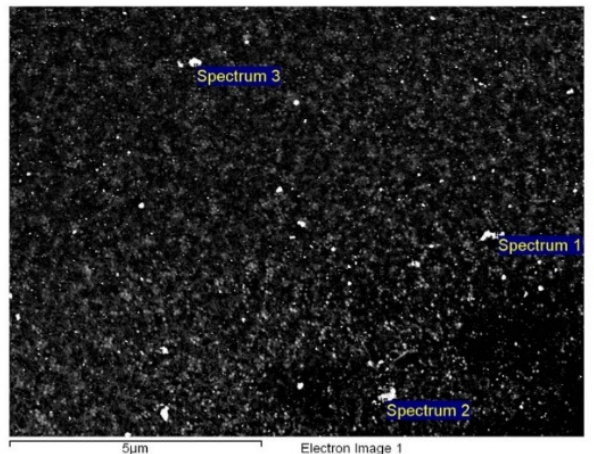

\begin{tabular}{|l|l|l|l|l|l|}
\hline Spectrum & C & O & Al & Si & $\mathrm{Au}$ \\
\hline Spectrum 1 & 32.32 & 40.85 & 11.17 & 9.11 & 6.55 \\
\hline Spectrum 2 & 29.45 & 41.39 & 14.52 & 8.78 & 5.86 \\
\hline Spectrum 3 & 23.84 & 42.74 & 13.29 & 12.92 & 7.20 \\
\hline
\end{tabular}

C)

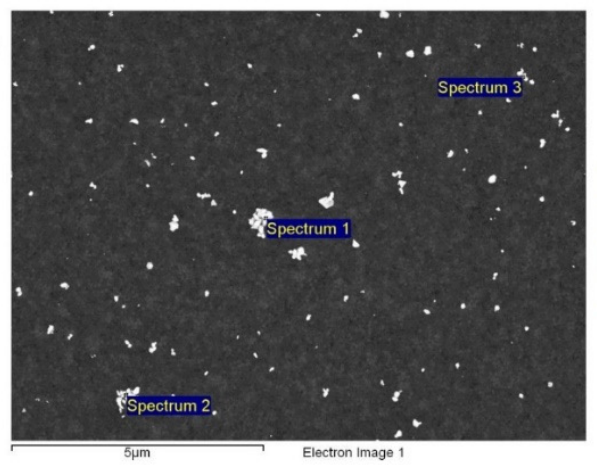

\begin{tabular}{|l|l|l|l|l|l|}
\hline Spectrum & $\mathrm{C}$ & $\mathrm{O}$ & $\mathrm{Al}$ & $\mathrm{Si}$ & $\mathrm{Au}$ \\
\hline Spectrum 1 & 18.39 & 41.17 & 8.44 & 13.53 & 18.46 \\
\hline Spectrum 2 & 18.16 & 41.72 & 7.85 & 14.88 & 17.39 \\
\hline Spectrum 3 & 17.40 & 48.74 & 9.09 & 16.09 & 8.67 \\
\hline
\end{tabular}

D)

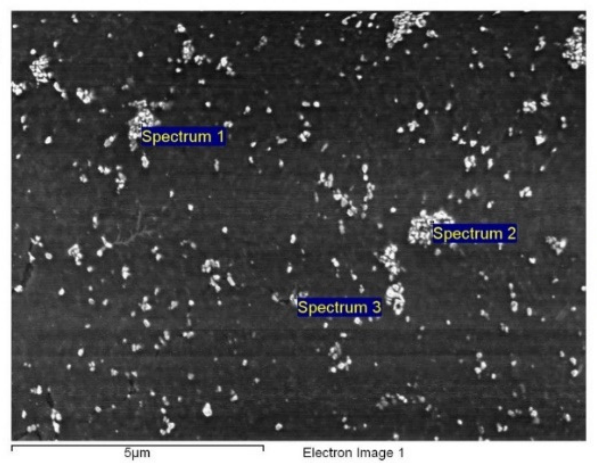

\begin{tabular}{|l|l|l|l|l|l|}
\hline Spectrum & $\mathrm{C}$ & $\mathrm{O}$ & $\mathrm{Al}$ & $\mathrm{Si}$ & $\mathrm{Au}$ \\
\hline Spectrum 1 & 32.32 & 40.85 & 11.17 & 9.11 & 6.55 \\
\hline Spectrum 2 & 29.45 & 41.39 & 14.52 & 8.78 & 5.86 \\
\hline Spectrum 3 & 23.84 & 42.74 & 13.29 & 12.92 & 7.20 \\
\hline
\end{tabular}

Figure 9. SEM/EDS studies of printed patterns on photo paper with precursor concentrations of: (A) AuCl $1 \mathrm{~g} / \mathrm{L}$, (B) AuCl $0.5 \mathrm{~g} / \mathrm{L}$, (C) AuAc $0.5 \mathrm{~g} / \mathrm{L}$, and (D) AuAc $1 \mathrm{~g} / \mathrm{L}$. The values are presented in weight percentages.

\section{Conclusions}

The following conclusions can be drawn from the current research work:

1. The USP synthesis, in combination with the rotavapor, allowed successful preparation of gold inks with AuNPs reaching Au concentrations more than 300 ppm.

2. SEM observation revealed that AuNPs in the as prepared inks had mostly spherical shape, with the presence of some irregularly shaped AuNPs. 
3. AuNPs in the prepared inks exhibited Z-average hydrodynamic diameters, ranging from 99 to $115 \mathrm{~nm}$.

4. Due to the fact that some AuNPs were over $1 \mu \mathrm{m}$ in size, consequently, the filtration of as prepared gold inks was mandatory to avoid problems with the inkjet printing, as AuNPs agglomerated, which can cause nozzle blockage.

5. After filtration, the AuNPs in gold inks had an average size between 20 and $46 \mathrm{~nm}$, suitable for inkjet printing. The AuNPs size was directly dependent on the $\mathrm{Au}$ concentration in the precursor (lower AuNPs' size-lower Au concentration).

6. The measured UV-VIS spectra of as prepared gold inks were within the range of $510-560 \mathrm{~nm}$.

7. The contact angle and surface energy results showed that the printed patterns could be controlled by varying the concentration of AuNPs in the inks.

8. The filtered gold inks were printed on photo paper with selected parameters, and it confirmed relative homogeneous distribution of AuNPs on their surfaces. Additional EDS measurements showed the presence of $\mathrm{Au}$.

Author Contributions: Conceptualization, H.R.T. and R.R.; methodology, H.R.T.; software, H.R.T., M.B., and P.M.; validation, H.R.T., P.M. and R.R.; formal analysis, H.R.T. and P.M.; investigation, H.R.T., M.B., and R.R.; resources, H.R.T. and R.R.; data curation, H.R.T. and P.M.; writing—original draft preparation, H.R.T., P.M., and R.R.; writing-review and editing, H.R.T., M.B., and R.R.; visualisation, H.R.T. and R.R.; supervision, R.R. and I.A.; project administration, R.R. and I.A.; funding acquisition, H.R.T. and R.R. All authors have read and agreed to the published version of the manuscript.

Funding: This research was funded by the Ministry of Education, Science and Sport, Republic of Slovenia and the European Union, The European Regional Development Fund (ERDF), Early research careers 2.1.

Conflicts of Interest: The authors declare no conflict of interest.

\section{References}

1. Lin, Y.; Gritsenko, D.; Liu, Q.; Lu, X.; Xu, J. Recent Advancements in Functionalized Paper-Based Electronics. ACS Appl. Mater. Interfaces 2016, 8, 20501-20515. [CrossRef] [PubMed]

2. Serpelloni, M.; Cantù, E.; Borghetti, M.; Sardini, E. Printed Smart Devices on Cellulose-Based Materials by means of Aerosol-Jet Printing and Photonic Curing. Sensors 2020, 20, 841. [CrossRef] [PubMed]

3. Brunetti, F.; Operamolla, A.; Castro-Hermosa, S.; Lucarelli, G.; Manca, V.; Farinola, G.M.; Brown, T.M. Printed Solar Cells and Energy Storage Devices on Paper Substrates. Adv. Funct. Mater. 2019, 29, 1806798. [CrossRef]

4. Gozutok, Z.; Kinj, O.; Torun, I.; Ozdemir, A.T.; Onses, M.S. One-step deposition of hydrophobic coatings on paper for printedelectronics applications. Cellulose 2019, 26, 3503-3512. [CrossRef]

5. Alkin, K.; Stockinger, T.; Zirkl, M.; Stadlober, B.; Bauer-Gogonea, S.; Kaltenbrunner, M.; Bauer, S.; Müller, U.; Schwödiauer, R. Paper-based printed impedance sensors for water sorption and humidity analysis. Flex. Print. Electron. 2017, 2, 14005. [CrossRef]

6. Öhlund, T.; Schuppert, A.K.; Hummelgård, M.; Bäckström, J.; Nilsson, H.-E.; Olin, H. Inkjet Fabrication of Copper Patterns for Flexible Electronics: Using Paper with Active Precoatings. ACS Appl. Mater. Interfaces 2015, 7, 18273-18282. [CrossRef]

7. Öhlund, T.; Örtegren, J.; Forsberg, S.; Nilsson, H.-E. Paper surfaces for metal nanoparticle inkjet printing. Appl. Surf. Sci. 2012, 259, 731-739. [CrossRef]

8. Wang, Y.; Yan, C.; Cheng, S.-Y.; Xu, Z.-Q.; Sun, X.; Xu, Y.-H.; Chen, J.-J.; Jiang, Z.; Liang, K.; Feng, Z.-S. Flexible RFID Tag Metal Antenna on Paper-Based Substrate by Inkjet Printing Technology. Adv. Funct. Mater. 2019, 29, 1902579. [CrossRef]

9. Yao, B.; Zhang, J.; Kou, T.; Song, Y.; Liu, T.; Li, Y. Paper-Based Electrodes for Flexible Energy Storage Devices. Adv. Sci. 2017, 4 , 1700107. [CrossRef]

10. Ling, H.; Chen, R.; Huang, Q.; Shen, F.; Wang, Y.; Wang, X. Transparent, flexible and recyclable nanopaper-based touch sensors fabricated via inkjet-printing. Green Chem. 2020, 22, 3208-3215. [CrossRef]

11. Wang, Y.; Guo, H.; Chen, J.; Sowade, E.; Wang, Y.; Liang, K.; Marcus, K.; Baumann, R.R.; Feng, Z. Paper-Based Inkjet-Printed Flexible Electronic Circuits. ACS Appl. Mater. Interfaces 2016, 8, 26112-26118. [CrossRef]

12. Beedasy, V.; Smith, P.J. Printed Electronics as Prepared by Inkjet Printing. Materials 2020, 13, 704. [CrossRef]

13. Ma, D.; Chon, S.; Cho, S.; Lee, Y.; Yoo, M.; Kim, D.; Lee, D.Y.; Lim, J.K. A novel photolithographic method for fabrication of flexible micro-patterned glucose sensors. J. Electroanal. Chem. 2020, 876, 114720. [CrossRef]

14. Dou, Y.; Chen, L.; Li, H.; Tang, B.; Henzen, A.; Zhou, G. Photolithography Fabricated Spacer Arrays Offering Mechanical Strengthening and Oil Motion Control in Electrowetting Displays. Sensors 2020, 20, 494. [CrossRef] 
15. Sameenoi, Y.; Nongkai, P.N.; Nouanthavong, S.; Henry, C.S.; Nacapricha, D. One-step polymer screen-printing for microfluidic paper-based analytical device ( $\mu$ PAD) fabrication. Analyst 2014, 139, 6580-6588. [CrossRef]

16. Somalu, M.R.; Muchtar, A.; Daud, W.R.W.; Brandon, N.P. Screen-printing inks for the fabrication of solid oxide fuel cell films: A review. Renew. Sustain. Energy Rev. 2017, 75, 426-439. [CrossRef]

17. Özkan, M.; Dimic-Misic, K.; Karakoc, A.; Hashmi, S.G.; Lund, P.; Maloney, T.; Paltakari, J. Rheological characterization of liquid electrolytes for drop-on-demand inkjet printing. Org. Electron. 2016, 38, 307-315. [CrossRef]

18. Ma, S.; Ribeiro, F.; Powell, K.; Lutian, J.; Møller, C.; Large, T.; Holbery, J. Fabrication of Novel Transparent Touch Sensing Device via Drop-on-Demand Inkjet Printing Technique. ACS Appl. Mater. Interfaces 2015, 7, 21628-21633. [CrossRef] [PubMed]

19. Tekin, E.; Smith, P.J.; Schubert, U.S. Inkjet printing as a deposition and patterning tool for polymers and inorganic particles. Soft Matter 2008, 4, 703-713. [CrossRef]

20. Van der Meulen, M.-J.; Reinten, H.; Wijshoff, H.; Versluis, M.; Lohse, D.; Steen, P. Nonaxisymmetric Effects in Drop-On-Demand Piezoacoustic Inkjet Printing. Phys. Rev. Appl. 2020, 13, 54071. [CrossRef]

21. Raut, N.C.; Al-Shamery, K. Inkjet printing metals on flexible materials for plastic and paper electronics. J. Mater. Chem. C 2018, 6, 1618-1641. [CrossRef]

22. Nayak, L.; Mohanty, S.; Nayak, S.K.; Ramadoss, A. A review on inkjet printing of nanoparticle inks for flexible electronics. J. Mater. Chem. C 2019, 7, 8771-8795. [CrossRef]

23. Arvizo, R.; Bhattacharya, R.; Mukherjee, P. Gold nanoparticles: Opportunities and challenges in nanomedicine. Expert Opin. Drug Deliv. 2010, 7, 753-763. [CrossRef] [PubMed]

24. Yeh, Y.C.; Creran, B.; Rotello, V.M. Gold nanoparticles: Preparation, properties, and applications in bionanotechnology. Nanoscale 2012, 4, 1871-1880. [CrossRef]

25. Mahato, K.; Nagpal, S.; Shah, M.A.; Srivastava, A.; Maurya, P.K.; Roy, S.; Jaiswal, A.; Singh, R.; Chandra, P. Gold nanoparticle surface engineering strategies and their applications in biomedicine and diagnostics. 3 Biotech 2019, 9, 57. [CrossRef]

26. Tiwari, P.M.; Vig, K.; Dennis, V.A.; Singh, S.R. Functionalized Gold Nanoparticles and Their Biomedical Applications. Nanomaterials 2011, 1, 31-63. [CrossRef] [PubMed]

27. Shariq, M.; Chattopadhyaya, S.; Rudolf, R.; Rai Dixit, A. Characterization of AuNPs based ink for inkjet printing of low cost paper based sensors. Mater. Lett. 2020, 264, 1-4. [CrossRef]

28. Shariq, M.; Marić, N.; Gorše, G.K.; Kargl, R.; Rudolf, R. Synthesis of gold nanoparticles with ultrasonic spray pyrolysis and its feasibility for inkjet printing on paper. Micro Nanosyst. 2018, 10, 102-109. [CrossRef]

29. Majerič, P.; Rudolf, R. Advances in Ultrasonic Spray Pyrolysis Processing of Noble Metal Nanoparticles-Review. Materials 2020, 13, 3485. [CrossRef]

30. Shariq, M.; Majerič, P.; Friedrich, B.; Budic, B.; Jenko, D.; Dixit, A.R.; Rudolf, R. Application of Gold(III) Acetate as a New Precursor for the Synthesis of Gold Nanoparticles in PEG Through Ultrasonic Spray Pyrolysis. J. Clust. Sci. 2017, 28, 1647-1665. [CrossRef]

31. Majerič, P.; Rudolf, R.; Friedrich, B.; Ternik, P. Numerical and experimental analysis of the single droplet evaporation in a ultrasonic spray pyrolysis device. Dry. Technol. 2018, 36, 11-20. [CrossRef]

32. Rudolf, R.; Majerič, P.; Štager, V.; Albreht, B. Process for the Production of Gold Nanoparticles by Modified Ultrasonic Spray Pyrolysis. Slovenia Patent Application No. P-202000079, 5 May 2020.

33. Della Volpe, C.; Siboni, S. Acid-base surface free energies of solids and the definition of scales in the Good-van Oss-Chaudhury theory. J. Adhes. Sci. Technol. 2000, 14, 235-272. [CrossRef]

34. Tiyyagura, H.R.; Majerič, P.; Anžel, I.; Rudolf, R. Low-cost synthesis of AuNPs through ultrasonic spray pyrolysis. Mater. Res. Express 2020,1,1-21. [CrossRef]

35. Abbas, A.; Bajwa, I. Inkjet Printing of Ag Nanoparticles using Dimatix Inkjet Printer, No 1. Protoc. Rep. 2017. [CrossRef]

36. Das, T.; Kolli, V.; Karmakar, S.; Sarkar, N. Functionalisation of Polyvinylpyrrolidone on Gold Nanoparticles Enhances Its Anti-Amyloidogenic Propensity towards Hen Egg White Lysozyme. Biomedicines 2017, 5, 19.

37. Trotsiuk, L.; Antanovich, A.; Lizunova, A.; Kulakovich, O. Direct synthesis of amphiphilic polyvinylpyrrolidone-capped gold nanoparticles in chloroform. Colloid Interface Sci. Commun. 2020, 37, 100289. [CrossRef]

38. Bhatti, Q.A.; Baloch, M.K.; Schwarz, S.; Petzold, G. Effect of Various Parameters on the Stability of Silica Dispersions. J. Solut. Chem. 2014, 43, 1916-1928. [CrossRef]

39. Guo, M.; Li, W.; Yang, F.; Liu, H. Controllable biosynthesis of gold nanoparticles from a Eucommia ulmoides bark aqueous extract. Spectrochim. Acta Part A Mol. Biomol. Spectrosc. 2015, 142, 73-79. [CrossRef]

40. Van Oss, C.J. Interfacial Forces in Aqueous Media, 2nd ed.; Routledge: London, UK, 2006; ISBN 9781420015768.

41. Knorr, S.D.; Combe, E.C.; Wolff, L.F.; Hodges, J.S. The surface free energy of dental gold-based materials. Dent. Mater. 2005, 21, 272-277. [CrossRef] 